\title{
Electronic medical record systems-based simulation for practicum in critical care nursing
}

\author{
Hiroshi Ota*1, Miki Inagaki ${ }^{2}$, Naoko Fujiwara $^{3}$, Masumi Azuma ${ }^{4}$ \\ ${ }^{1}$ Faculty of Nursing, Shijonawate Gakuen University, Osaka, Japan \\ ${ }^{2}$ Faculty of Nursing, Setsunan University, Osaka, Japan \\ ${ }^{3}$ Faculty of Nursing, Senri kinran University, Osaka, Japan \\ ${ }^{4}$ Faculty of Nursing, Kobe Women's University, Kobe, Japan
}

Received: September 25, 2017

DOI: $10.5430 /$ jnep.v8n4p96
Accepted: November 30, 2017 Online Published: December 8, 2017

URL: https://doi.org/10.5430/jnep.v8n4p96

\begin{abstract}
Electronic medical record (EMR) systems are increasingly used in medical facilities. This study focused on nursing students' information-gathering ability, an important skill in emergency nursing where patients' conditions can change rapidly. A simulation exercise was developed based on an educational EMR system and conducted as part of the nursing process exercises that prepare students for on-site practical emergency nursing training. The utility of the EMR system and the educational effectiveness of the simulation exercise were evaluated. To this end, 106 third-year nursing students were surveyed twice: once after they participated in the simulation exercise and once after they undertook their practical training. The results showed that the students evaluated the EMR system's operability favorably, suggesting that the system has potential as a prototype. Regarding the conditions of the simulation exercise, the results suggested that designing the learning environment so that it features a scenario encountered in practical training settings was effective for helping the students envisage the conditions of practical training.
\end{abstract}

Key Words: Electronic medical record systems, Simulation, Nursing

\section{INTRODUCTION}

Recent advances in information and communications technology (ICT) have brought major changes to healthcare. The introduction of electronic medical record (EMR) systems has helped healthcare organizations to standardize, share, and apply medical information. In addition to streamlining healthcare operations, EMR systems serve as tools for managing the quality of healthcare; sharing patient information; and supporting diagnosis, treatment, and patient briefings. Data obtained from EMRs can be combined and collated with other information, creating big data that can be used in medical education and research. In the United States, 74.1\% of medical facilities have an EMR system ${ }^{[1]}$ while $41.4 \%$ of Japanese medical facilities have one. ${ }^{[2]}$ In Japan, there is a national drive to increase the use of EMRs.

The problems people deal with when using ICT were included in the 2013 Adult Skills Survey by the Organization for Economic Co-operation and Development (OECD)'s Program for the International Assessment of Adult Competence (PIAAC). The PIAAC categorized such problems within the domain of problem solving in technology-rich environments, which it identified as one of the key information-processing skills alongside literacy and numeracy. ${ }^{[3]}$ In the survey, it was found that $63 \%$ of the total population had at least level-1 Japan. 
proficiency in problem solving in technology-rich environments (ICT, etc.), meaning that they can operate basic applications like user-friendly software and web browsers. It was also found that $34 \%$ of the respondents had at least level-2 proficiency, where they could use generic applications and specialized application. These results indicate that, despite the proliferation of ICT-based learning environments, ICT proficiency is uneven, suggesting steps should be taken to ensure a more even use of ICT in education. The current nursing students who will go on to use an EMR system when they enter practice have been raised in a digital technologyrich environment, but a recent study highlights a lack of information-gathering proficiency among university students in Japan, ${ }^{[4]}$ suggesting that this ability needs to be developed through university curricula.

Nursing students will have to operate an EMR system when they start practical training. However, nurses will encounter a range of problems when they start using an EMR system, including restrictions on availability and number of devices, the volume of patient information, and the level of their information-gathering ability. A review of the recent literature on the use of EMRs in medical training reveals that there are a number of teaching reports regarding learning content on the basic information items and operation of EMR systems. ${ }^{[5-8]}$ However, these reports are primarily on system development, post-installation follow-up, and learning outcomes. Few studies focus on the use of an educational EMR system to equip students with information-gathering ability. Additionally, no studies have examined the utility of an EMR system in simulation learning or the educational effectiveness of an exercise that simulates the conditions of practical training.

This study focused on nursing students' informationgathering ability, an important skill in emergency nursing where patients' conditions change rapidly. A simulation exercise based on an educational EMR system was developed and conducted as part of the nursing process skills exercises that prepare nurses for practical emergency nursing training. The utility of the EMR system and the educational effectiveness of the simulation exercise were evaluated.

\section{Simulation OVERVieW}

\subsection{Nursing process exercises}

The simulation exercise was conducted in one of the 90minute-long nursing process (perioperative) classes, which are part of 30 classes in the "adult nursing: assessment and skills" course for third-year students. There were eight 90minute-long nursing process classes, consisting of assessment methods, EMR simulation exercise information, assess- ment, target setting, planning-and-assessment, and conference. A flipped classroom approach was used for all the exercises.

\subsection{Simulation exercise}

In the simulation exercise, the students had to gather information using the educational EMR system. Pairs of students used a PC and data sheets like those used in on-site training. The class time was divided into briefings on the data sheets and EMR operation (10 minutes) and information gathering (70 minutes). Midway through the exercise, the instructors checked the students' progress, advised them on how to view and enter data, and prompted them to exchange opinions with each other. There were two instructors. After the class, there was a 90-minute period in which the students could use the PCs freely and view the data.

\subsection{Educational EMRs}

\subsubsection{System design}

The EMRs' inventory items had user-friendly icons and explanations in web font. The system was designed to be responsive and capable of displaying information in the same format as the university intranet. Regarding the setup of the patient information, for the convenience of the instructors, the case inventory items (prepared using writing software) were converted into PDF format and enabled to be adjusted by linking. HTML and CSS3 were used for the markup language. Regarding the network, each PC used the university's cloud server.

\subsubsection{EMR Inventory Items}

The study included 15 inventory items in the EMR system: Patient profile, nursing database, doctor instructions, progress chart, progress record, ICU record, surgical operation/operative nursing record, rehabilitation, medication, injections, measures, $\mathrm{x}$-ray, body examination, physiological examination, and other (see Table 1).

The case was selected after deliberation on the kinds of surgery that the students would frequently encounter in their practical training and the ultimate decision to use a case involving a trans-cervical fracture patient who received a bipolar hip replacement. The information on this patient covered a three-day period from admission (one day before surgery) to the day after surgery.

\section{METHODS}

\subsection{Study period and participants}

The study was conducted between May of 2015 and March of 2016 with 106 third-year nursing students. 
Table 1. Data included in educational EMR system

\begin{tabular}{|c|c|}
\hline Patient information categories and contents & $\begin{array}{l}\text { Amount of words } \\
\text { (Japanese) }\end{array}$ \\
\hline [Patient profile] & 230 words \\
\hline [Nursing database] Gordon’s functional health patterns & 2,400 words \\
\hline [Doctor instructions] Instructions during hospitalization, instructions for pain and other emergencies & 1,400 words \\
\hline [Progress chart] Vital signs, eating/excretion volume, check items & - \\
\hline [Progress record] POS-based narrative record keeping & 6,400 words \\
\hline [ICU record] Progress during care in ICU (in the case used in the exercise, the ICU record was blank) & 15 words \\
\hline [Surgical operation/operative nursing record] & 2,900 words \\
\hline [Rehabilitation plan] & 800 words \\
\hline [Medication] & 180 words \\
\hline [Injections] & 230 words \\
\hline [Measures] & 170 words \\
\hline [X-ray] Image data & 110 words \\
\hline [Body examination] & 400 words \\
\hline [Physiological examination] & 110 words \\
\hline [Other] Surgery briefing, informed consent form, etc. & 1,600 words \\
\hline
\end{tabular}

\subsection{Study procedure and analysis method}

Two surveys were conducted: one after the simulation exercise and one after the practical training. The first survey (post-simulation) inquired into the EMR training environment (time and number of devices), the EMR's operability, and how useful it was in preparing the students for practical training. The second survey (post-practice) inquired into how the simulation exercise experience affected practical training. Responses were rated on a 5-point scale (yes, to a great extent; yes; more or less; no; absolutely not). The second survey included additional open-ended questions. The first of these questions concerned the problems the participants encountered when operating and gathering information from the EMR system in their practical training, and the second concerned the participants' comments about the university's training exercises and classes for teaching about how to operate the EMR and gather information on it during practical training. Descriptive statistics and SPSS ver.21.0 were used for analysis.

\subsubsection{Post-simulation survey items}

- Q1 Did you have enough time to use the EMR?

- Q2 Was the EMR easy to use?

- Q3 Was the EMR exercise useful for independent learning?

- Q4 Was the EMR exercise useful for group learning?

- Q5 Do you feel that the EMR exercise will be useful in onsite settings?

\subsubsection{Post-practical survey}

- Q6 Do you think your experience with the EMR simulation exercise helped you in the practical training?

- Q7 Did you feel that the conditions and restrictions of the EMR simulation exercise were similar to the conditions you experienced in practical training?

\subsection{Ethical considerations}

The participants received verbal and written briefings detailing the study's purpose and method, the fact that refusal to participate would not bring any disadvantage, that willingness or unwillingness to participate would not affect the participants' academic record, and that anonymity was guaranteed. Participants indicated their consent by responding to the questionnaire survey. The study was approved by the research ethics committee of the authors' university.

\section{Results}

The response rate was $38.7 \%(n=41)$ for the post-simulation survey and $69.8 \%(n=74)$ for the post-practical survey.

\subsection{Post-simulation survey}

Regarding the results for the post-simulation survey, $36.6 \%$ of the respondents answered the question "did you have enough time to use the EMR" in the affirmative (yes, to a great extent; yes; or more or less), and $82.9 \%$ and $95.1 \%$ affirmatively answered "was the EMR easy to use" and "do you feel that the EMR exercise will be useful in on-site settings," respectively (see Table 2 ).

\subsection{Post-practical survey}

Regarding the results for the post-simulation survey, $82.3 \%$ of the respondents answered affirmatively to "do you think your experience in the EMR exercise helped you in the practical training", and $66.2 \%$ answered affirmatively to "did you feel that the conditions and restrictions of the EMR simulation exercise were similar to the conditions you experienced in practical training?" (see Tables 3 and 4).

ISSN 1925-4040 E-ISSN 1925-4059 
Table 2. Survey results: Post-simulation survey

\begin{tabular}{|c|c|c|c|c|c|}
\hline Question item & $\begin{array}{l}\text { Yes, to a } \\
\text { great extent }\end{array}$ & Yes & $\begin{array}{l}\text { More or } \\
\text { less }\end{array}$ & No & $\begin{array}{l}\text { Absolutely } \\
\text { not }\end{array}$ \\
\hline Q1. Did you have enough time to use the EMR? & $2(4.9)$ & $5(12.2)$ & $8(19.5)$ & $20(48.8)$ & $6(14.6)$ \\
\hline Q2. Was the EMR easy to use? & $8(19.5)$ & $11(26.8)$ & $15(36.6)$ & $5(12.2)$ & $2(4.9)$ \\
\hline Q3. Was the EMR exercise useful for independent learning? & $5(12.2)$ & $13(31.7)$ & $16(39.0)$ & $6(14.6)$ & $1(2.4)$ \\
\hline Q4. Was the EMR exercise useful for group learning? & $6(14.6)$ & $10(24.4)$ & $21(51.2)$ & $2(4.9)$ & $2(4.9)$ \\
\hline Q5. Do you feel that the EMR exercise will be useful in onsite settings? & $14(34.1)$ & $13(31.7)$ & 12 (29.3) & $1(2.4)$ & $1(2.4)$ \\
\hline
\end{tabular}

Table 3. Survey results: Post-practical survey $(n=74)$

\begin{tabular}{|c|c|c|c|c|c|}
\hline Question item & $\begin{array}{l}\text { Yes, to a } \\
\text { great extent }\end{array}$ & Yes & $\begin{array}{l}\text { More or } \\
\text { less }\end{array}$ & No & $\begin{array}{l}\text { Absolutely } \\
\text { not }\end{array}$ \\
\hline $\begin{array}{l}\text { Q6. Do you think your experience with the EMR simulation exercise } \\
\text { helped you in the practical training? }\end{array}$ & $16(21.6)$ & $16(21.6)$ & 29 (39.1) & 11 (14.9) & $2(2.8)$ \\
\hline $\begin{array}{l}\text { Q7. Did you feel that the conditions and restrictions of the EMR } \\
\text { simulation exercise were similar to the conditions you experienced } \\
\text { in practical training? }\end{array}$ & $12(16.2)$ & $16(21.6)$ & $21(28.4)$ & 25 (33.8) & $0(0)$ \\
\hline
\end{tabular}

Table 4. Survey results: Post-practical survey; free descriptive responses

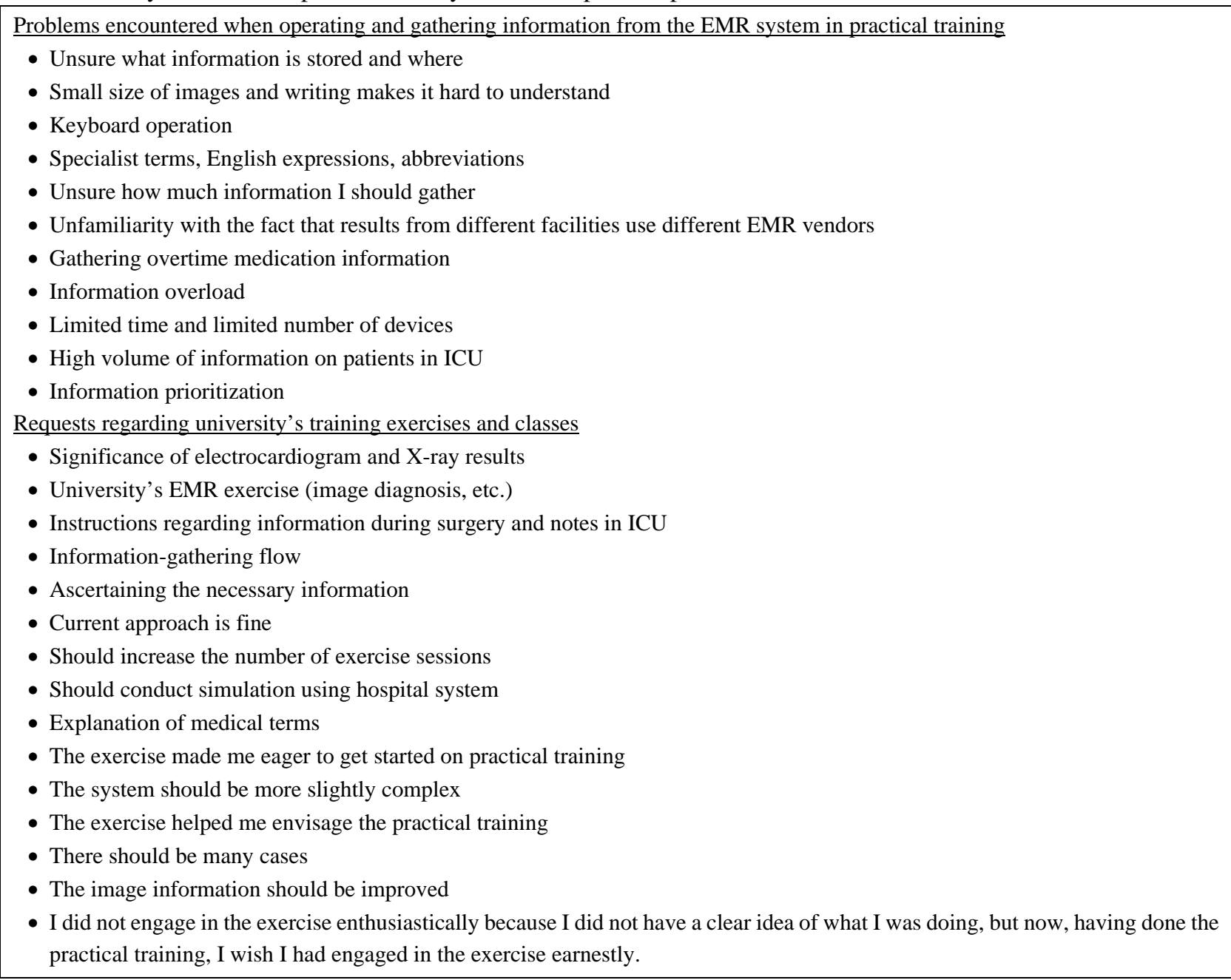


As for the open-ended answers, in response to the question about the problems the participants encountered when operating and gathering information from the EMR system in their practical training, many referred to information-gathering strategy and how the EMR system in the simulation exercise differed from the system they encountered in hospital in terms of data volume and system. In response to the question about the participants' comments about the university's training exercises and classes for teaching about how to operate the EMR and gather information on it during practical training, the participants mentioned exercise opportunities and specific information-gathering strategies.

\section{Discussion}

\subsection{The usefulness of the simulation exercise}

Many of the participants assessed the EMR system's operability favorably. The design of the EMR's interface, including its user-friendly icons and web font, meant that, even with the students' limited prior experience in operating an EMR, they could use the system effectively without experiencing difficulties in the first step. As the free-descriptive answers indicate, during their practical training, the students found the actual EMR systems more complex due to the volume of information, the use of specialist terminology and abbreviations, and the visual information. These findings have implications for the design of an EMR system for the pretraining simulation exercises-namely, that, while making such an educational EMR system as intuitive as possible, it is also important to consider the disparity in patient data volume between the educational system and the actual EMR systems that students will encounter in practical training. For the simulation exercise, this study only included patient information covering three days (day of admission to day after surgery). Actual EMR systems include a much greater range of patient information, including disease history, treatment progress, and past hospitalization information. Additionally, the visual presentation of the information differs depending on the EMR vendor. To minimize the "reality shock" in practical training, it might be necessary to introduce a variety of cases, increase case complexity, and use different layouts for the same cases.

The students tended to evaluate the simulation exercise conditions favorably on the basis that these conditions resembled the conditions of practical training. Having considered the students' responses in prior practical training, the study allocated 70 minutes to viewing time. Many students reported that this was an insufficient amount of time to use the EMR system in the simulation exercise. Despite this, a relatively large number of the students gave favorable responses to the question "did you feel that the conditions and restrictions of the EMR exercises were similar to the conditions you experienced in practical training?" Such responses support the instructors' deliberate attempt to recreate the conditions of practical training. Despite the disparity in usage environment between the simulation exercise-EMR system and the EMR systems encountered in practical training, it is believed that the simulation exercise helped the students envisage an information-gathering strategy for practical training and was, thus, educationally effective.

\subsection{The usefulness of the simulation exercise in relation to practical training}

Regarding the students' attitudes toward the usefulness of the simulation exercise, the responses in both surveys were positive. The responses were particularly favorable in the post-practical survey with over $80 \%$ of the students reporting that the simulation was effective. Thus, the surveys indicate that the simulation exercise was useful in preparing the students for practical training. Simulation-based learning is useful for helping learners acquire knowledge experientially as educators can consider the learners' knowledge and technical readiness and design and implement the simulation accordingly. To this end, it is necessary to design the class in such a way that the learning from the exercise is shared and deepened; this may include planned preliminary learning, holding briefings, and holding separate debriefings.

The survey results indicate that students are unsure about how to gather the information necessary to prepare a nursing support plan. With their limited knowledge and experience, students struggle to gather information systematically and to judge what information to select and what to reject. As such, they are prone to gathering information in a heteronomous and random manner. To address this problem, educators should instruct students so that they understand the check items that are necessary for assessment and can search through the information with a clear goal in mind. Supplementary instruction, such as briefings and debriefings, will be an effective measure to achieve this.

\section{Conclusions}

The results showed that the students evaluated the EMR system's operability favorably, suggesting that the system has potential as a prototype. Regarding the conditions of the simulation exercise, the results suggested that designing the learning environment so that it features a scenario encountered in practical training settings was effective for helping the students envisage the conditions of practical training. Looking ahead, alongside efforts to refine to the system itself, it will be effective to examine the optimal design of simulation learning classes. 


\section{ACKNOWLEDGEMENTS}

This work was supported by JSPS KAKENHI Grant Number $15 \mathrm{~K} 11534$.

\section{CONFLICTS OF INTEREST Disclosure}

\section{REFERENCES}

[1] Chun-Ju H, Esther H. NCHS Data Brief No.143, Use and Characteristics of Electronic Health Record Systems Among Office-based Physician Practices: United States, 2001-2013. 2014. Available from: https://www.cdc.gov/nchs/data/databriefs/db143.pdf

[2] Ministry of Health, Labour and Welfare. ICT Utilization of Health and Medical and Nursing Field. 2015. (Japanese) Available from: http://www.mhlw.go.jp/file/06-Seisakujouh ou-12600000-Seisakutoukatsukan/0000075101.pdf

[3] The Organisation for Economic Co-operation and Development, OECD. Programme for the International Assessment of Adult Competencies (PIAAC). 2013. Available from: http://www. oecd.org /site/piaac/surveyofadultskills.htm

[4] Tsuru N. A study on the information literacy of undergraduate students, Seijo University economic papers. 2008; 180: 119-140. (Japanese)
[5] Doi H, Yamamoto C, Yoshida M, et al. Practicing nursing techniques using case studies of the educational electronic medical chart system and nurse reporting: Students' self-evaluation of on campus practice. International Nursing Care Research. 2017; 13(4): 179-185. (Japanese)

[6] Doi H, Yamamoto C, Sugimoto Y, et al. Nursing students' selfevaluation in education on electronic chart systems: Five years since the development of educational materials. The Bulletin of Niimi College. 2013; 34: 21-25. (Japanese)

[7] Ueyama K, Uno F, Doi H. Nursing students' awareness of information collection using an electronic chart system and its operation (No.2); A survey of training in pediatric nursing after introducing an electronic chart training system. The Bulletin of Niimi College. 2010; 31: 67-72. (Japanese)

[8] Hirota M, Sekinaga N. Differences in the level of students' achievement in the implementation of nursing procedures between two hospitals in which they are and are not granted the right of access to an electronic medical record system. Aino Journal. 2015; 13: 83-87. 